\title{
Spectral rarefaction: linking ecological variability and plant species diversity
}

\author{
D. Rocchini ${ }^{1,2,4}$, T. Wohlgemuth $^{3}$, S. Ghisleni ${ }^{1}$ and A. Chiarucci ${ }^{1,2}$ \\ ${ }^{1}$ Dipartimento di Scienze Ambientali “G. Sarfatti”, Università di Siena, via P. A. Mattioli 4, 53100, Siena, Italy \\ ${ }^{2}$ TerraData environmetrics, Dipartimento di Scienze Ambientali "G. Sarfatti”, Università di Siena, \\ via P.A. Mattioli 4, 53100, Siena, Italy \\ ${ }^{3}$ WSL Swiss Federal Institute for Forest, Snow and Landscape Research, Zürcherstrasse 111, CH-8903 Birmensdorf, \\ Switzerland \\ ${ }^{4}$ Corresponding author. E-mail: rocchini@unisi.it, Fax: +390577232896
}

Keywords: Biodiversity, Landsat ETM+, Satellite imagery, Species rarefaction, Species richness, Species turnover, Spectral rarefaction, Spectral Variation Hypothesis.

\begin{abstract}
Species rarefaction curves have long been used for estimating the expected number of species as a function of sampling effort and they represent a powerful tool for quantifying the diversity of an area from local ( $\alpha$-diversity) to regional scale ( $\beta$ - and $\gamma$-diversity). Nonetheless, sampling species based on standard plant inventories represents a cost expensive approach. In this view, remotely sensed information may be straightforwardly used for predicting species rich sites. In this paper, we present spectral rarefaction, i.e., the rarefaction of reflectance values derived from satellite imagery, as an effective manner for predicting bio-diverse sites. We tested this approach in ten biogeographical subregions in Switzerland. Plant species data were derived from the Swiss 'Biodiversity Monitoring' programme (BDM), which represents species richness of Switzerland at the landscape scale by a systematic sample of 520 quadrats of $1 \mathrm{~km} \times 1 \mathrm{~km}$. Seven Landsat ETM+ images covering the whole study area were acquired. Species and spectral rarefaction were built and results were compared by Pearson correlation coefficient considering several sampling efforts (as measured by the number of sampled quadrats). Local $\alpha$-diversity showed a similar pattern considering the ten biogeographical subregions while $\beta$ - and $\gamma$-diversity showed higher values for regions in the Alpine arc and lower values for plateau regions and Jura mountains on the strength of the higher ecological (and spectral) variability of the former areas. Meanwhile, positive correlations between species and spectral richness values were significant only after a certain amount of area was accumulated, thus indicating a scale dependence of the fit of satellite and species data. With this paper, we introduce spectral rarefaction as an effective tool in quantifying diversity at a range of spatial scales. Obviously, the achieved results should be viewed as an aid to plan field survey rather than to replace it. We propose to use worldwide available remotely sensed information as a driver for field sampling design strategies.
\end{abstract}

Abbreviations: BDM - BioDIversity Monitoring, DN - Digital Number, ETM - Enhanced Thematic Mapper.

\section{Introduction}

Species diversity investigation is a crucial task when dealing with biodiversity estimate and conservation (Rodrigues et al. 2004). In fact, both species richness (hereafter even referred to as $\alpha$-diversity) and turnover ( $\beta$-diversity) represent powerful indicators of ecological conditions because of their intrinsic relation with ecological heterogeneity (Magurran 1983, Stoms and Estes 1993, Gaston 2000). In this view, species rarefaction curves demonstrated their usefulness in estimating the expected number of species as a function of sampling effort, quantified by the number of individuals or quadrats sampled (Gotelli and Colwell 2001, Koellner et al. 2004). These curves have also been used to obtain estimates of species richness based on a standardised sampling effort, allowing both valid comparisons between inventories and the estimation of the minimum sampling effort required to reach a satisfactory level of completeness (Moreno and Halffter 2001).
Measuring species richness on the basis of a standard sampling effort represents a cost expensive approach (Palmer et al. 2002). From this point of view, ancillary variables based on remotely sensed information could represent a powerful tool for predicting species rich sites (Gillespie et al. 2008). Remote sensing has been used to predict species rich sites based on spectral heterogeneity of remotely sensed data (as summarised by the Spectral Variation Hypothesis, SVH see Palmer et al. 2002) considering different types of taxa, such as vascular plants (see e.g., Gould 2000, Foody and Cutler 2003, Fairbanks and McGwire 2004, Rocchini et al. 2004, Foody and Cutler 2006), lichens (Waser et al. 2004) or even mammals (Oindo and Skidmore 2002). However, previous tests of the SVH were substantially based on predictive regression models of species richness vs. spectral variability at local scale, considering only $\alpha$-diversity (see e.g., Rocchini et al. 2004, Foody and Cutler 2006, Rocchini 2007b), even if some examples exist about the investigation of $\alpha$-diversity 
with increasing local grain (Kumar et al. 2006). To date, few efforts have been made to relate ecological heterogeneity measured by remote sensing to the other components of species diversity, such as $\beta$ - and $\gamma$-diversity taking into account the species turnover over the whole extent of a study area (see e.g., Tuomisto et al. 2003, Rocchini et al. 2005, Rocchini 2007a, Rocchini and Cade in press).

The aim of this paper is to test if spectral variability estimated by the accumulation of different spectral values represents a good proxy of species variability measured by species rarefaction curves considering a wide range of scales.

\section{Study area}

The study area is the whole Switzerland, which covers $41244 \mathrm{~km}^{2}$ in central Europe and ranges in altitude from 193 to $4634 \mathrm{~m}$ a.s.1. $\left(45^{\circ} 49^{\prime}-47^{\circ} 48^{\prime} \mathrm{N}\right.$ latitude, $5^{\circ} 57^{\prime}-10^{\circ} 30^{\prime} \mathrm{E}$ longitude, Fig. 1). The average elevation is $1300 \mathrm{~m}$ a.s.1. Mountain landscapes predominate, with $60 \%$ of the country being formed by the Alps and $10 \%$ by the Jura Mountains. About $7 \%$ of the country consists of urban settlements including buildings, associated green areas, and road and rail networks (BFS 1992/1997). Switzerland can be easily subdivided into three parts: the Alps, the Jura Mountains and the Central Plateau between them. A finer classification based on similarities of vascular plants and insects (Gonseth et al. 2001) consists of 10 biogeographical subregions (Table 1), with six subregions in the Alps and three subregions in the Central Plateau. The Jura Mountains remain a unique region at this level.

\section{Methods}

\section{Field data}

The Swiss 'Biodiversity Monitoring' programme (BDM) uses indicators of pressure, state and response. In total, 11 state indicators ( $\mathrm{Z}$ for German 'Zustand') are repeatedly assessed. The Z7 indicator observes the diversity of vascular plants on a landscape scale using a systematic sample of $5201 \mathrm{~km} \times 1 \mathrm{~km}$ quadrats. Spacing between neighbour quadrats was $19.1 \mathrm{~km}$ in most regions and $14.3 \mathrm{~km}$ in the Southern Alps and the Jura Mountains (Hintermann et al. 2000). The BDM aims, among other objectives, to survey landscape biodiversity - from lowland to alpine zones - over a long period. In the quadrats, data were collected along 2500 $\mathrm{m}$ long transect routes, in buffers of $2.5 \mathrm{~m}$ on both sides of the transect (Plattner et al. 2004). All sample quadrats had been visited for a first assessment by the end of 2005 .

\section{Satellite data}

Seven ortho-Landsat ETM+ images taken in the summer period and covering the whole Switzerland (spanning a period from 1999 to 2001) were acquired. Theoretically, a large difference between the time of satellite image acquisition and field survey could affect the relations between spectral values and species composition (Rocchini 2007a). However, in this case, the temporal gap between images and field data should not threaten the results, because of the large grain of the quadrats and the longer time expected for vegetation dynamics. Moreover, considering the extent of the study area, gen-

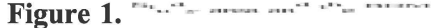

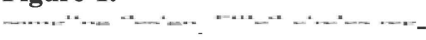

…

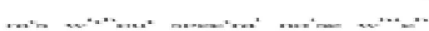

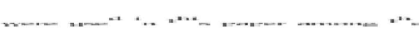

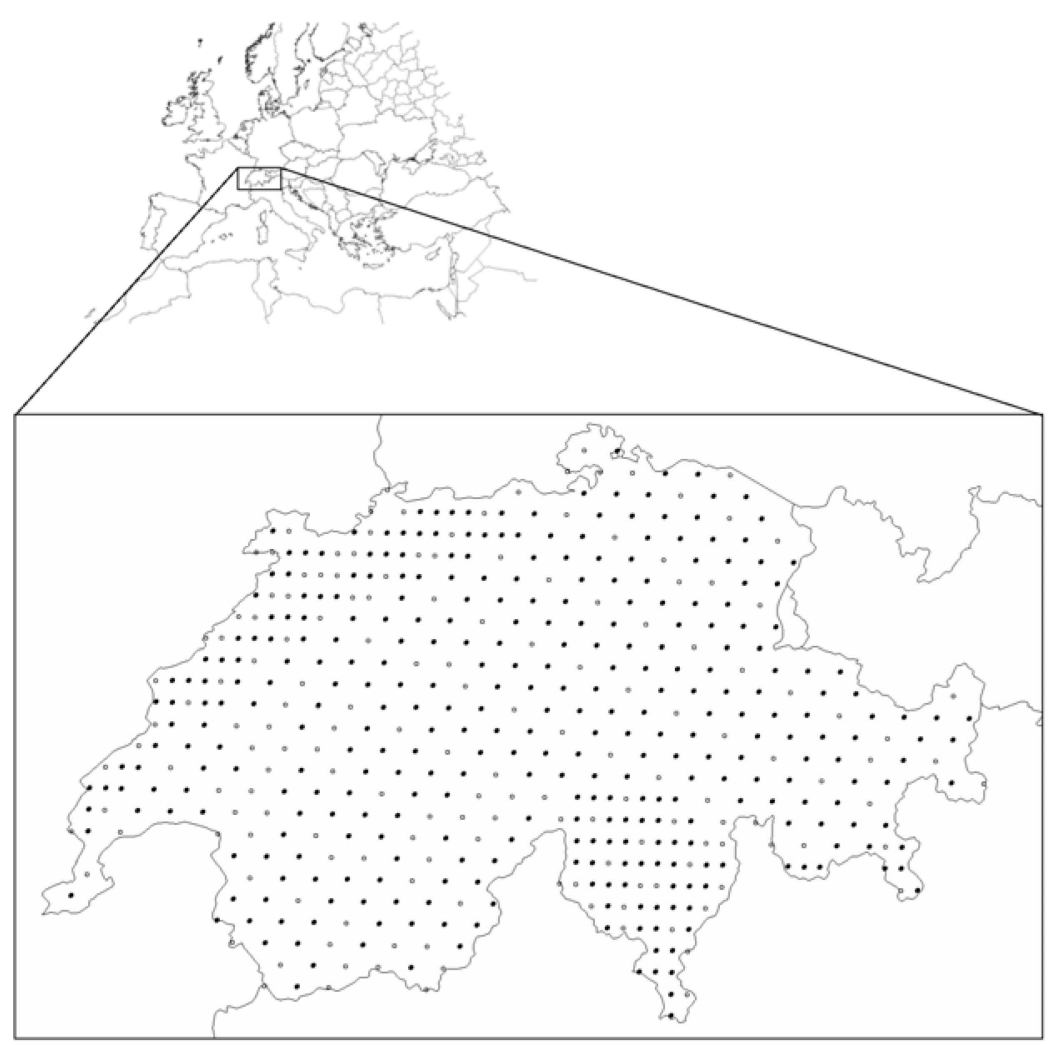


Table 1.

\begin{tabular}{llc}
\hline Biogeographical region & Biogeographical subregion & Number of sampling units \\
\hline Jura Mountains & Jura Mountains & 82 \\
Plateau & High Rhine/Lake Geneva & 19 \\
& Central Plateau West & 48 \\
Alps & Central Plateau East & 42 \\
& Northern Alps & 85 \\
& Northern Alps Foothills & 22 \\
& Central Alps West & 38 \\
& Central Alps East & 56 \\
& Southern Alps & 41 \\
& Southern Alps Foothills & 30 \\
\hline
\end{tabular}

eral patterns were tested in this paper, thus discarding isolated disturbance situations.

Spatial resolution of Landsat ETM+ multispectral sensor equals $30 \mathrm{~m}$ while spectral resolution covers an electromagnetic range of $0.45-2.35 \mu \mathrm{m}$ (considering bands 1-5 and 7). Thermal Infrared (band 6) having a spatial resolution of 60 $\mathrm{m}$ was not used in this paper. The radiometric resolution is 8 bit, i.e., with a theoretical range of 0-255 values (Digital Numbers, hereafter DNs) per band. To reduce atmospheric effects a dark-object subtraction was applied to each image (Chavez 1988, 1996). Such a relative radiometric correction involves subtracting a constant DN value from the entire image. The theoretical assumption of dark object subtraction is that due to atmospheric scattering satellite sensors should record a non zero DN value for dark objects with $0 \%$ reflectance. Such a DN value is thus subtracted from each band.

\section{Species and spectral rarefaction}

Among the 520 quadrats of the previously described assessment of vascular plants in the frame of the BDM, 463 quadrats free from spectral noise (e.g., clouds, shadows, etc...) were retained for further analysis. The number of units per biogeographical subregion is reported in Table 1.

Species rarefaction curves for each biogeographical subregion were achieved by using the R software (vegan package, Oksanen et al. 2007) according to the following equation:

$$
E[S]=S-\frac{\sum_{i=1}^{S}\left(\begin{array}{c}
N-N_{i} \\
n
\end{array}\right)}{\left(\begin{array}{l}
N \\
n
\end{array}\right)}
$$

where $N$ is the total number of quadrats, $N_{i}$ is the number of quadrats where species $i$ is found, $n$ is the number of randomly selected quadrats, $S$ refers to the total number of species within all the quadrats (see Kobayashi 1974, Koellner et al. 2004, Chiarucci et al. 2008).

Similarly to species rarefaction curves, the number of accumulated spectral DN for a given sample size (number of plots) was expressed by applying the rarefaction formula to the spectral DNs, rather than species counts. Since, as for species rarefaction, spectral rarefaction is based on one-dimensional values, an unstandardised PCA was applied to extract the one-dimensional data set mostly related to the origi- nal Landsat ETM+ bands. Accordingly, the first PCA axis (PC1), explaining $71 \%$ of the variance of the whole multispectral dataset, was retained for further analysis. Noteworthy, a PCA axis contains continuous values, and these cannot be used as classes for rarefaction purposes. For this reason, PC1 was converted into a 8-bit band splitting values into 256 equal intervals by Rmcdr R-package (Fox et al. 2007). This range was arbitrarily chosen on the strength of the input radiometric resolution ( $8 \mathrm{bit}=256$ values), but other ranges could even be adopted (see Le Hégarat-Mascle et al. 1997). This choice does not impact the analyses, since the interest is focused on relative differences among biogeographical subregions. Consequently, for each quadrat, formed by 1089 pixels on average, the number of different DNs could theoretically range from 1 (homogeneous environment such as water) to 256 (heterogeneous environment composed by different land cover classes). Notice that a maximum number of DNs lower than 256 per quadrat is expected on the strength of the spatial autocorrelation of spectral values. Once spectral rarefaction curves are built, the number of $\mathrm{DN}$ values per quadrat can be directly estimated $\left(\alpha_{\mathrm{DN}}\right)$ and rises until theoretically reaching a value of 256 while new quadrats are added to the curve. Obviously the theoretical maximum of 256 different values is reached only when the considered biogeographical subregion is so heterogeneous that it comprises all the 256 values obtained by the first PCA axis.

To graphically represent $\alpha$-, $\beta$ - and $\gamma$-diversity of the achieved rarefaction curves and overall to compare the ten biogeographical subregions, a rectangle was overlapped on the curve as in Fig. 2. The $y$ dimension of the rectangle represents the whole diversity components considering an additive partitioning of $\gamma$-diversity. Such a theoretical formula $(\gamma$ $=\alpha+\beta$, see Lande 1996) allows to represent all the diversity components in the same measurement units (Wagner et al. 2000) and has been widely applied in the ecological literature (see e.g., Gering et al. 2003, Ricotta 2005, Crist and Veech 2006, Pelissier and Couteron 2007, Veech and Crist 2007). Within the proposed example (Fig. 2) the lowest and highest $y$ values of the vertical side of the rectangle correspond to the $\alpha$ - and $\gamma$-diversity while the length of the side corresponds to the $\beta$-diversity.

Species and spectral rarefaction curves per biogeographical subregion were compared considering pairs of accumulated species and DNs per region. The rarefaction curves of the ten subregions differed in length because of the different size per subregion. Thus, we chose the range of 1 to 


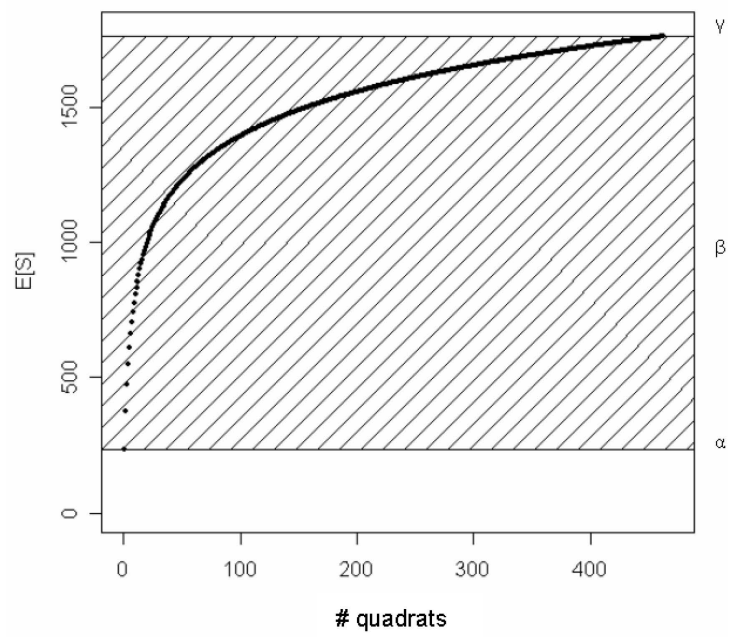

Figure 2. $\cdots \ldots+\cdots+\cdots$

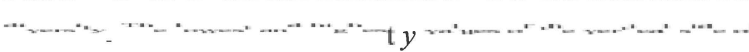

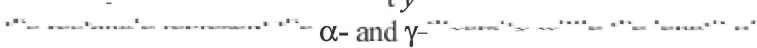
$\beta$-diversity.
19 quadrats, which equals the number of quadrats in the smallest subregion (Table 1). In fact, comparisons among areas need to consider the same minimum "sampling effort" (hereafter referred to as $S_{m}$, in this case equalling to 19, Table 1). A correlation analysis between species $E[S]$ and spectral $\mathrm{E}[\mathrm{DN}]$ estimated richness was carried out to test similarities of species vs. spectral diversity. In particular, Pearson coefficient was calculated for an increasing number of quadrats (with $S_{m}$ as maximum number) considering all the biogeographical subregions $(N=10)$.

\section{Results}

Species richness per quadrat in the different biogeographical subregions ( $\alpha$-diversity) showed a similar value of about 200 species (Fig. 3). On the contrary, quadrats in the Alps (Northern, Central and Southern Alps) showed higher total species richness $\left(\gamma_{S m}\right)$, ranging from 791 to 921 species, and species turnover $\left(\beta_{S m}\right)$, ranging from 537 to 713 species. Jura Mountains and Central Plateau areas (High Rhine/Lake Geneva and Central Plateau East and West, Fig

\section{Species rarefaction}
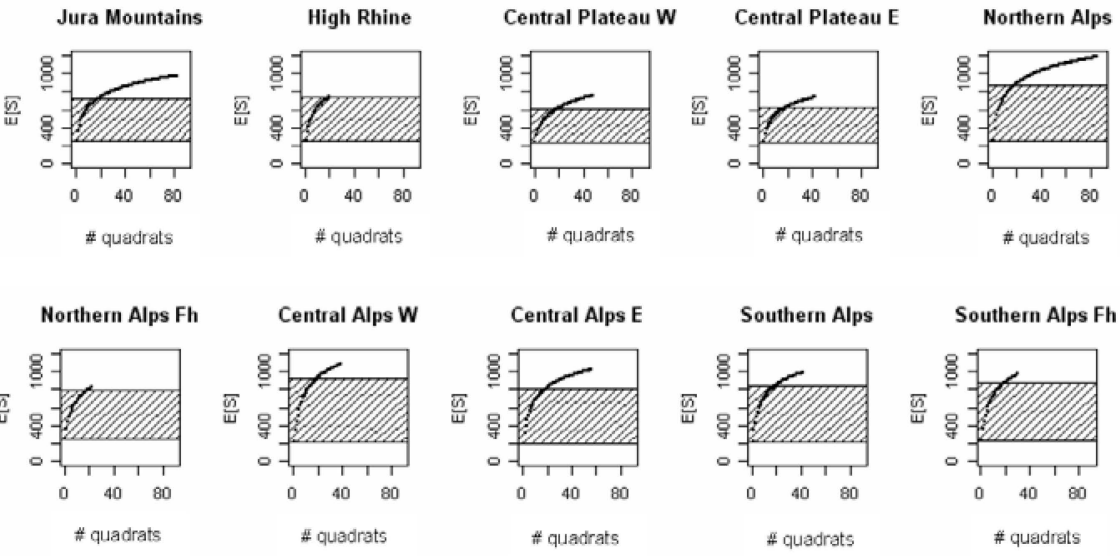

Southern Alps Fh

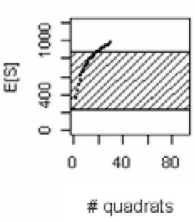

\section{Spectral rarefaction}
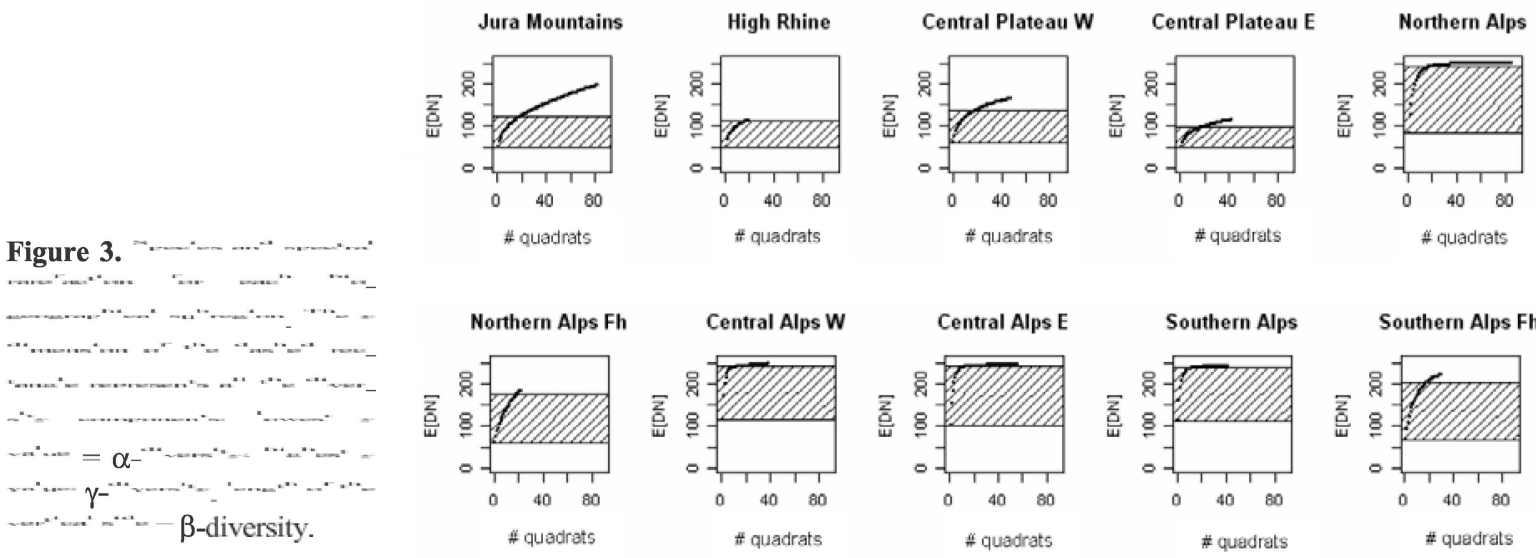


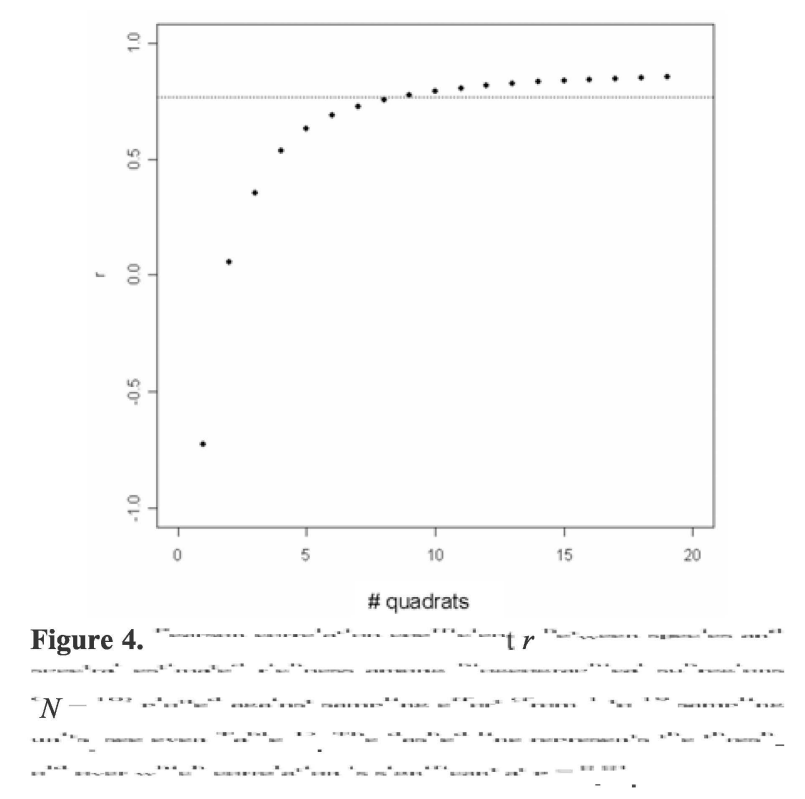

3) showed slightly lower values of $\gamma_{S m}$ and $\beta_{S m}$ ranging from 610 to 735 species $\left(\gamma_{S m}\right)$ and from 386 to 488 species $\left(\beta_{S m}\right)$.

Considering spectral variability, quadrats in the Alps were generally more diverse than quadrats in the Jura Mountains and Central Plateau. Contrary to the species richness pattern, local spectral heterogeneity $\left(\alpha_{\mathrm{DN}}\right)$ showed a distinctive pattern with higher mountains being more spectrally diverse at local scale. In fact, Northern, Central and Southern Alps showed high $\alpha_{\mathrm{DN}}$ values ranging from 85 to 114 different DNs. On the contrary, quadrats of the Jura Mountains, the Plateau and foothills of both side of the Alps showed lower $\alpha_{\mathrm{DN}}$ values ranging from 48 to 65 different DNs. Considering $\gamma_{D N, S m}$, and $\beta_{\mathrm{DN}, S m}$ the same pattern achieved for species rarefaction was obtained for DNs rarefaction. The Alps (including foothills) showed higher values of $\gamma_{\mathrm{DN}, S m}$, ranging from 174 to 241 , and $\beta_{\mathrm{DN}, S m}$, ranging from 114 to 156 different DNs (Fig. 3). Jura Mountains and Central Plateau areas showed slightly lower values of both $\gamma_{\mathrm{DN}, \mathrm{Sm}}$, ranging from 98 to 136 , and $\beta_{\mathrm{DN}, \mathrm{Sm}}$, ranging from 49 to 76 different $\mathrm{DNs}$ (Fig. 3).

In summary, quadrats in the Alps showed higher values of $\gamma$ - and $\beta$-diversity, considering both species and spectral rarefaction (Fig. 3). Notice that the highest $y$ value of the rectangle and the length of its vertical side (Fig. 3), representing $\gamma$ - and $\beta$-diversity, are slightly diverse considering the Alps on the one hand and Jura/Plateau on the other, considering both species and spectral rarefaction. The unique difference between species and spectral rarefaction is that local scale diversity $(\alpha)$ showed no differences among biogeographical subregions considering species counts, while it was slightly higher in Alps considering DN counts. This phenomenon became apparent when considering the correlation among the ten subregions between species and spectral values, given the same sampling effort. The Pearson coefficient of correlation was negative, even if statistically not significant, at the scale of one single quadrat and grew up to a statistically significant positive correlation after a certain amount of area was accumulated (Fig. 4).

\section{Discussion}

Mountainous regions in Switzerland are richer in plant species than low-elevation regions (Wohlgemuth 1993). In general, habitat heterogeneity at the landscape scale including species pools for lowland and mountain plants is the main reason for this pattern (Wohlgemuth 1998). The Jura Mountains and the Alps regions, ranging from ca. 500 to $1600 \mathrm{~m}$ a.s.1. and from 200 to $4600 \mathrm{~m}$ a.s.1. respectively, are richer than the lower elevated Central Plateau because, in the latter region, mountain species (reflecting a different habitat type) are absent. At the scale of $1 \mathrm{~km}^{2}$, species richness in Switzerland peaks in quadrats with mean elevation of about 1200 $1300 \mathrm{~m}$ a.s.1. (Wohlgemuth et al. 2008).

The results achieved in this study indicated that spectral rarefaction is a powerful tool for detecting regionally different biodiversity. This is because with respect to many scales (number of quadrats), spectral rarefaction positively correlates with species rarefaction. While at the regional scale the two measures of diversity were statistically correlated, a weak correlation was found when considering few steps of the rarefaction curves only. Moreover, at the local scale $(\alpha-$ diversity) a negative correlation was achieved, thus contrasting with the previously described Spectral Variation $\mathrm{Hy}$ pothesis (SVH); the non significant $p$-value of such a correlation suggested a rejection of the SVH. However, this result may be a statistical artefact deriving from the adopted sampling design rather than a real response pattern of species richness vs. spectral variability. In fact, considering that vascular plant species richness in the quadrats referred to the number of species recorded along transects, this does not represent the whole species richness of a given quadrat, but only a list of particularly frequent species (Stohlgren et al. 1997a). Transects are not ideal for capturing species richness because patchy species and rare habitats are often missed (Stohlgren 2007). Therefore, while consistently collected among bioregions, some bioregions may contain more rare habitats or more patchily distributed species than others. This may result in an underestimate of the real $\alpha$-diversity within each quadrat (Palmer 1995) and in a consequent levelling of the differences among quadrats. Some evidence of this is represented by the basically equal average $\alpha$-diversity visible in the species rarefaction curves, in all the different biogeographical subregions.

Spectral rarefaction brings both advantages and disadvantages in its very nature. Considering the latter, it should be applied with caution mainly because of scale problems in matching ground and satellite imagery. An inappropriate matching of satellite spatial resolution and the grain of field data could hide actual spatial heterogeneity with sub-pixel variability remaining undetected (Small 2004, Rocchini 2007b). In this sense, the use of hyperspectral satellite images at coarse spatial resolution like MODIS, whose pixel size approximates that of the sampling quadrats adopted 
here, may hide the variability of an area simply because of the high amount of mixed pixels which hampers to detect fine grained patterns (Fisher 1997). It is well known that a phenomenon could be undetected only because the scale of analysis is not appropriate for study of such phenomenon (Stohlgren et al. 1997a). Moreover, one should consider multiple scales during the analysis process from field unit grain to the whole extent of the study area to detect both accordance and possible discrepancies between species richness and spectral variability (see Stohlgren et al. 1997a, Stohlgren et al. 1997b, Wu et al. 2000 about the importance of applying multiscale approaches to diversity estimate). In this paper, the use of correlation analysis applied to a continuous change of sampling effort represented a straightforward methodology for solving such an issue.

Advantages of the spectral rarefaction technique mainly arise from its implicit capability in estimating landscape (ecological) heterogeneity from the local to the regional scale in such a way that it may visualise scaling up properties. This should allow to individuate heterogeneous areas a priori during the planning phase of species inventorying or monitoring programs. Considering species inventory issues, once landscape heterogeneous areas have been identified by spectral rarefaction, sampling designs weighted on landscape heterogeneity could be built to improve species inventory efficiency (Rocchini et al. 2005). Plant species assessment in relatively large areas has always been an important task for plant ecologists, including or excluding common standards in measuring the completeness of the resulting species lists and in quantifying the sampling effort (see e.g., Palmer 1995, Palmer et al. 2002). As stated by Palmer et al. (2002), accurately inventorying species over a large region is complicated by the fact that the botanists cannot inspect every individual plant in the region and that species composition changes through time (Robinson et al. 1994, Kirby and Thomas 2000, McCollin et al. 2000). Different methods have been proposed to locate those environmental gradients offering the maximum change in species richness (e.g., Gillison and Brewer 1985, Rocchini et al. 2005). Noteworthy, subjective sampling is likely to outperform any objective sampling in terms of maximising plant species inventories (Palmer et al. 2002). However, replicable methods for inventorying species are strongly encouraged for improving statistical estimates of species richness (Chiarucci et al. 2001, 2003, D'Alessandro and Fattorini 2002, Baffetta et al. 2007), large scale evaluation and comparison (Koellner et al. 2004, Chiarucci and Bonini 2005), and multitemporal monitoring (Ferretti and Chiarucci 2003, Kalkhan et al. 2007).

In this paper, spectral values rather than classified images were directly used which maintains the continuous information. In most studies using remotely sensed images, predictors of species variability were mainly based on landscape metrics derived from remote sensing classification (Stohlgren et al. 1997b). Of course, image classification allows to estimate not only landscape compositional variability, like in the present paper, but even structural variability over space by applying landscape structural metrics like shape indices or interspersion (see e.g., Kumar et al. 2006). However, as stressed by Palmer et al. (2002) and Schwarz and Zimmermann (2005), processing remote sensing data may lead to a loss of information. In fact, as long as the used classes contain a high degree of reflectance mixture, endmembers (i.e., pixels occupied solely by one cover type) do not accurately represent actual ecological patterns (see Townshend et al. 2004 on the matter). This inevitably leads to the application of several techniques based on robust theoretical background for classifying images avoiding Boolean memberships, basically relying on mixture modelling (Small 2005, Shanmugam et al. 2006, Nichol and Wong 2007) or on fuzzy classification (Foody 1996, Woodcock and Gopal 2000, Tang et al. 2005, Okeke and Karnieli 2006, Rocchini and Ricotta 2007). On the contrary, the results achieved in this paper promote satellite imagery as continuous ancillary data with high potential for predicting species richness.

\section{Conclusions}

Spectral rarefaction curves are demonstrated to be adequate proxies for species rarefaction curves, with an improved fit with a larger number of sampling units. Obviously, the achieved results should be viewed as a help to plan field survey rather than a replacement of it, limiting remote information as a driver for field sampling design strategies. Spectral heterogeneity has been previously demonstrated to have a sort of predictive power with respect to species richness within a given site, at different spatial scales (Gould 2000, Oindo and Skidmore 2002, Rocchini et al. 2004). Further, Rocchini et al. (2005) demonstrated that species complementarity among sites ( $\beta$-diversity), i.e., ecological gradients, can also be maximised by spectral variability. By this paper, we introduce spectral rarefaction as an effective tool in quantifying diversity at a range of spatial scales.

Acknowledgements: We are particularly grateful to G. Bacaro and C. Ricotta for precious insights about the models used in the present paper. We also thank A. Billi, M. Giordano and A. Nucci for their huge work on data acquirement and analysis. A particular thank is due to the Handling Editor E. Feldmeyer and to an anonymous Referee for useful insights on the paper.

\section{References}

Baffetta, F., G. Bacaro, L. Fattorini, D. Rocchini and A. Chiarucci. 2007. Multi-stage cluster sampling for estimating average species richness at different spatial grains. Community Ecol. 8: 119$\underline{127 .}$

BFS (1992/1997) Arealstatistik. Bundesamt für Statistik, Servicestelle GEOSTAT, Neuchâtel, Switzerland.

Chavez, P.S. Jr. 1988. An improved dark object subtraction technique for atmospheric scattering correction of multispectral data. Remote Sensing of Environment 24: 459-479.

Chavez, P.S. Jr. 1996. Image based calibration revisited and improved. Photogrammetric Engineering \& Remote Sensing 62: 1025-1036. 
Chiarucci, A., G. Bacaro, D. Rocchini and L. Fattorini. 2008. Discovering and rediscovering the sample-based rarefaction formula in the ecological literature. Community Ecol. 9: 121-123.

Chiarucci, A. and I. Bonini. 2005. Quantitative floristics as a tool for the assessment of plant diversity in Tuscan forests. Forest Ecol. Manage. 212: 160-170.

Chiarucci, A., N.J. Enright, G.L.W. Perry, B.P. Miller and B.B. Lamont. 2003. Performance of nonparametric species richness estimators in a high diversity plant community. Diversity and Distributions 9: 283-295.

Chiarucci, A., S. Maccherini and V. De Dominicis. 2001. Evaluation and monitoring of the flora in a nature reserve by estimation methods. Biol. Conserv. 101: 305-314.

Crist, T.O. and J.A. Veech. 2006. Additive partitioning of rarefaction curves and species-area relationships: unifying alpha-, beta- and gamma-diversity with sample size and habitat area. Ecol. Lett. 9: 923-932.

D'Alessandro, L. and L. Fattorini. 2002. Resampling estimators of species richness from presence-absence data: why they don't work. Metron 61: 5-19.

Fairbanks, D.H.K. and K.C. McGwire. 2004. Patterns of floristic richness in vegetation communities of California: regional scale analysis with multi-temporal NDVI. Global Ecol. Biogeogr. 13: 221-235.

Ferretti, M. and A. Chiarucci. 2003. Design concepts adopted in long-term forest monitoring programs in Europg: problems for the future? The Science of the Total Environment 310: 171-178.

Fisher, P. 1997. The pixel: a snare and a delusion. International J. Remote Sensing 18: 679-685

Foody, G.M. 1996. Fuzzy modelling of vegetation from remotely sensed imagery. Ecol. Model. 85: 3-12.

Foody, G.M. and M.E.J. Cutler. 2003. Tree biodiversity in protected and logged Bornean tropical rain forests and its measurement by satellite remote sensing. J. Biogeogr. 30: 1053-1066.

Foody, G.M. and M.E.J. Cutler. 2006. Mapping the species richness and composition of tropical forests from remotely sensed data with neural networks. Ecol. Model. 195: 37-42.

Fox, J., M. Ash, T. Boye, S. Calza, A. Chang, P. Grosjean, R. Heiberger, G.J. Kerns, R. Lancelot, M. Lesnoff, S. Messad, M. Maechler, D. Putler, M. Ristic, and P. Wolf. 2007. Rcmdr: $R$ Commander. $\mathrm{R}$ package version 1.2-9. http://www.r-project.org, http://socserv.socsci.mcmaster.ca/jfox/Misc/Rcmdr/.

Gaston, K.J. 2000. Global patterns in biodiversity. Nature 405: 220227.

Gering, J.C., T.O. Crist and J.A. Veech. 2003. Additive partitioning of species diversity across multiple spatial scales: implications for regional conservation of biodiversity. Conserv. Biol. 17: 488-499.

Gillespie, T.W., G.M. Foody, D. Rocchini, A.P. Giorgi and S. Saatchi. 2008. Measuring and modeling biodiversity from space. Progress in Physical Geography, in press.

Gillison, A.N. and K.R.W. Brewer. 1985. The use of gradient directed transects or gradsects in natural resource surveys. J. Environmental Manage. 20: 103-127.

Gonseth, Y., T. Wohlgemuth, B. Sansonnens and A. Buttler. 2001. Die Biogeographischen Regionen der Schweiz. Erläuterungen und Einteilungsstandard / Les régions biogéographiques de la Suisse. Explications et division standard. Umwelt Materialien / Cahiers de l'environment 137: $47 \mathrm{~S}$.
Gotelli, N.J. and R.K. Colwell. 2001. Quantifying biodiversity: procedures and pitfalls in the measurement and comparison of species richness. Ecol. Lett. 4: 379-391.

Gould, W. 2000. Remote Sensing of vegetation, plant species richness, and regional biodiversity hot spots. Ecol. App. 10: 18611870.

Hintermann, U., D. Weber and A. Zangger. 2000. Biodiversity monitoring in Switzerland. Schriftenreihe für Landschaftspflege und Naturschutz 62: 47-58.

Kalkhan, M.A., E.J. Stafford and T.J. Stohlgren. 2007. Rapid plant diversity assessment using a pixel nested plot design: A case study in Beaver Meadows, Rocky Mountain National Park, Colorado, USA. Diversity and Distributions 13: 379-388.

Kirby, K.J. and R.C. Thomas. 2000. Changes in the ground flora in Wytham Woods, southern England from 1974 to 1991 - implications for nature conservation. J. Veg. Sci. 11: 871-880.

Kobayashi, S. 1974. The species-area relation I. A model for discrete sampling. Res. Popul. Ecol. 15: 223-237.

Koellner, T., A.M. Hersperger and T. Wohlgemuth. 2004. Rarefaction method for assessing plant species diversity on a regional scale. Ecography 27: 532-544.

Kumar, S., T.J. Stohlgren and G.W. Chong. 2006. Spatial heterogeneity influences native and nonnative plant species richness. Ecology 87: 3186-3199.

Lande, R. 1996. Statistics and partitioning of species diversity, and similarity among multiple communities. Oikos 76: 5-13.

Le Hégarat-Mascle, S., D. Vidal-Madjar, O. Taconet and M. Zribi. 1997. Application of Shannon information theory to a comparison between L- and C-band SIR-C polarimetric data versus incidence angle. Remote Sensing of Environment 60: 121-130.

Magurran, E.M. 1983. Ecological Diversity and its Measurement. Chapman and Hall, London.

McCollin, D., L. Moore and T. Sparks. 2000. The flora of a cultural landscape: environmental determinants of change using archival sources. Biol. Conserv. 92: 249-263.

Moreno, C.E. and G. Halffter. 2001. On the measure of sampling effort used in species accumulation curves. J. App. Ecol. 38: 487-490.

Nichol, J. and M.S. Wong. 2007. Remote sensing of urban vegetation life form by spectral mixture analysis of high-resolution IKONOS satellite images. International Journal of Remote Sensing 28: 985-1000.

Oindo, B.O. and A.K. Skidmore. 2002. Interannual variability of NDVI and species richness in Kenya. International Journal of Remote Sensing 23: 285-298.

Okeke, F. and A. Karnieli. 2006. Methods for fuzzy classification and accuracy assessment of historical aerial photographs for vegetation change analyses. Part I: Algorithm development. International Journal of Remote Sensing 27: 153-176.

Oksanen, J., R. Kindt, P. Legendre and R.B. O’Hara. 2007. Vegan: Community Ecology Package version 1.8-6. http://cran.r-project.org/.

Palmer, M.W. 1995. How should one count species? Natural Areas Journal 15: 124-135.

Palmer, M.W., P. Earls, B.W. Hoagland, P.S. White and T. Wohlgemuth. 2002. Quantitative tools for perfecting species lists. Environmetrics 13: 121-137.

Pelissier, R. and P. Couteron. 2007. An operational, additive framework for species diversity partitioning and beta-diversity analysis. J. Ecol. 95: 294-300. 
Plattner, M., S. Birrer and D. Weber. 2004. Data quality in monitoring plant species richness in Switzerland. Community Ecol. 5: 135-143.

Ricotta, C. 2005. Additive partitioning of Rao's quadratic diversity: a hierarchical approach. Ecol. Model. 183: 365-371.

Robinson, G.R., M.E. Yurlina and S.N. Handel. 1994. A century of change in the Staten island flora: ecological correlates of species losses and invasions. Bull. Torrey Bot. Club 121: 119-129.

Rocchini, D. 2007a. Distance decay in spectral space in analysing ecosystem $\beta$-diversity. International Journal of Remote Sensing 28: 2635-2644.

Rocchini, D. 2007b. Effects of spatial and spectral resolution in estimating ecosystem $\alpha$-diversity by satellite imagery. Remote Sensing of Environment 111: 423-434.

Rocchini, D., S. Andreini Butini and A. Chiarucci. 2005. Maximizing plant species inventory efficiency by means of remotely sensed spectral distances. Global Ecol. Biogeogr. 14: 431-437.

Rocchini, D. and B. Cade. in press. Quantile regression applied to spectral distance decay. IEEE Geoscience and Remote Sensing Letters. doi: 10.1109/LGRS.2008.2001767.

Rocchini, D., A. Chiarucci and S.A. Loiselle. 2004. Testing the spectral variation hypothesis by using satellite multispectral images. Acta Oecol. 26: 117-120.

Rocchini, D. and C. Ricotta. 2007. Are landscapes as crisp as we may think? Ecol. Model. 204: 535-539.

Rodrigues, A.S.L., S.J. Andelman, M.I. Bakarr, L. Boitani, T.M. Brooks, R.M. Cowling, L.D.C. Fishpool, G.A.B. da Fonseca, K.J. Gaston, M. Hoffmann, J.S. Long, P.A. Marquet, J.D. Pilgrim, R.L. Pressey, J. Schipper, W. Sechrest, S.N. Stuart, L.G. Underhill, R.W. Waller, M.E.J. Watts and X. Yan. 2004. Effectiveness of the global protected area network in representing species diversity. Nature 428: 640-643.

Schwarz, M. and N.E. Zimmermann. 2005. A new GLM-based method for mapping tree cover continuous fields using regional MODIS reflectance data. Remote Sensing of Environment 95: 428-443.

Shanmugam, P., Y.H. Ahn and S. Sanjeevi. 2006. A comparison of the classification of wetland characteristics by linear spectral mixture modelling and traditional hard classifiers on multispectral remotely sensed imagery in southern India. Ecol. Model. 194: 379-394.

Small, C. 2004. The Landsat ETM+ spectral mixing space. Remote Sensing of Environment 93: 1-17.

Small, C. 2005. A global analysis of urban reflectance. International Journal of Remote Sensing 26: 661-681.

Stohlgren, T.J. 2007. Measuring Plant Diversity: Lessons from the Field. Oxford University Press, New York, USA.

Stohlgren, T.J., G.W. Chong, M.A. Kalkhan and L.D. Schell. 1997a. Multiscale sampling of plant diversity: effects of minimum mapping unit size. Ecol. App. 7: 1064-1074.
Stohlgren, T.J., M.B. Coughenour, G.W. Chong, D. Binkley, M.A. Kalkhan, L.D. Schell, D.J. Buckley and J.K. Berry. 1997b. Landscape analysis of plant diversity. Landsc. Ecol. 12: 155$\underline{170 .}$

Stoms, D.M. and J.E. Estes. 1993. A remote sensing research agenda for mapping and monitoring biodiversity. International Journal of Remote Sensing 14: 1839-1860.

Tang, X.M., W. Kainz and Y. Fang. 2005. Reasoning about changes of land covers with fuzzy settings. International Journal of Remote Sensing 26: 3025-3046.

Townshend, J.R.G., C. Huang, S.N.V. Kalluri, R.S. Defries, S. Liang and K. Yang. 2004. Beware of per-pixel characterization of land cover. International Journal of Remote Sensing 21: 839-843.

Tuomisto, H., A.D. Poulsen, K. Ruokolainen, R.C. Moran, C. Quintana, J. Celi and G. Cañas. 2003. Linking floristic patterns with soil heterogeneity and satellite imagery in Ecuadorian Amazonia. Ecol. App. 13: 352-371.

Veech, J.A. and T.O. Crist. 2007. Habitat and climate heterogeneity maintain beta-diversity of birds among landscapes within ecoregions. Global Ecol. Biogeogr. 16: 650-656.

Wagner, H.H., O. Wildi and K.C. Ewald. 2000. Additive partitioning of plant species diversity in an agricultural mosaic landscape. Landsc. Ecol. 15: 219-227.

Waser, L.T., S. Stofer , M. Schwarz , M. Küchler, E. Ivits and C.H. Scheidegger . 2004. Prediction of biodiversity: regression of lichen species richness on remote sensing data. Community Ecol. 5: 121-134.

Wohlgemuth, T. 1993. The distribution atlas of pteridophytes and phanerograms of Switzerland (Welten and Sutter 1982) in a relational database - species number per mapping unit and its dependence on various factors. Bot. Helv. 103: 55-71.

Wohlgemuth, T. 1998. Modelling floristic species richness on a regional scale: A case study in Switzerland. Biodiversity and Con servation 7: 159-177.

Wohlgemuth, T., M. Nobis, F. Kienast and M. Plattner. 2008. Modelling vascular plant diversity at the landscape scale using systematic samples. J. Biogeogr. 35: 1226-1240.

Woodcock, C.E. and S. Gopal. 2000. Fuzzy set theory and thematic maps: accuracy assessment and area estimation. International Journal of Geographical Information Science 14: 153-172.

Wu, J., D.E. Jelinski, M. Luck and P.T. Tueller. 2000. Multiscale analysis of landscape heterogeneity: scale variance and pattern metrics. Geographic Information Sciences 6: 6-19. 